\section{CITAÇÃO}

Magano, G. (2020)

Visita virtual ao Museu da Farmácia,

Rev. Ciência Elem., V8(04):064.

doi.org/10.24927/rce2020.064

\section{EDITOR}

José Ferreira Gomes,

Universidade do Porto

\section{EDITOR CONVIDADO}

João Lopes dos Santos

Universidade do Porto

\section{RECEBIDO EM}

02 de dezembro de 2020

\section{ACEITE EM}

14 de dezembro de 2020

\section{PUBLICADO EM}

15 de dezembro de 2020

\section{COPYRIGHT}

(C) Casa das Ciências 2020.

Este artigo é de acesso livre, distribuído sob licença Creative Commons com a designação CC-BY-NC-SA 4.0, que permite a utilização e a partilha para fins não comerciais, desde que citado o autor e a fonte original do artigo.

rce.casadasciencias.org

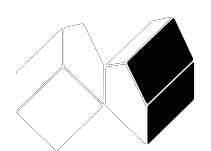

\title{
Visita virtual ao Museu da Farmácia
}

\section{Gonçalo Magano}

Museu da Farmácia

O século XXI introduziu novos conceitos na área da museologia. Os museus, antes considerados conservadores, e apenas disponíveis àqueles que se deslocassem até eles, começaram a ver no mundo digital, uma oportunidade de potenciar aquilo que é a sua maior vocação: a divulgação do seu património e atividade cultural. A era digital abriu portas à internacionalização das coleções, antes apenas feita através de publicações e catálogos. Desde a criação de websites, à utilização das redes sociais enquanto plataformas de divulgação, compreendeu-se uma rápida adesão dos museus (nacionais e internacionais) ao mundo digital. Aqueles que o fizeram mais prontamente, encontraram neste trabalho uma ferramenta pronta a combater a atual situação pandémica, continuando a disponibilizar a sua oferta cultural, ainda que de portas encerradas. 0 Museu da Farmácia, nesta altura, lançava, sob o lema \#culturasemquarentena, um conjunto de iniciativas para chegar até aos seus seguidores através do mundo digital.

O Museu da Farmácia abriu portas ao público no ano de 1996, em Lisboa, com o desejo de dar a conhecer a história da saúde e da farmácia. Ao longo de 24 anos, e já após a inauguração de um segundo polo, na cidade do Porto, tem sido ambição do Museu da Farmácia reunir peças dos quatro cantos do mundo, de forma a permitir que os seus visitantes se aventurem por entre 5000 anos de história: desde o primeiro contacto do homem com a saúde, na pré-história, até às mais recentes viagens espaciais da NASA, que no Museu da Farmácia ganham vida através de equipamentos que estiveram a bordo do Space Shuttle Endeavour.

0 ano de 2020 fica marcado pelo primeiro Estado de Emergência da história da democracia portuguesa, que teve como consequência o encerramento provisório dos museus nacionais. De forma a dar resposta à emergência cultural, o Museu da Farmácia procurou começar a conceber a Visita Virtual ao Museu da Farmácia, que no mês de novembro se tornou realidade: uma viagem imersiva e interativa, que pode ser feita na segurança da escola ou mesmo em casa de cada aluno. Trata-se de uma visita mediada em tempo real, que nos transporta entre as várias coleções do Museu da Farmácia Lisboa e Porto, de forma a dar a conhecer diferentes civilizações, crenças, teorias, objetos, através das histórias que nos vídeos apresentados ganham vida. Uma visita que, à semelhança das tradicionais visitas guiadas, permite uma interação constante com o guia, abrindo espaço não apenas ao esclarecimento de dúvidas e questões, como também à interação através de questionários que são colocados em diversos momentos da visita. 
A experiência inicia-se pelos Primórdios da Farmácia, onde, através de peças emblemáticas como o Sarcófago de Irtierut (FIGURA 1) ou a vasta Coleção de Vasos Gregos, é traçado o percurso das primeiras grandes civilizações, como o Antigo Egipto, a Grécia Antiga e até o Império Romano, através dos testemunhos que estas nos deixaram na área da saúde. Seguem-se Os Contrastes da Idade Média, onde são apresentadas as diferenças entre a Europa medieval, que assiste ao crescimento da Igreja Católica, e o Mundo Árabe, que no seu florescimento encontra não apenas novas fórmulas farmacêuticas, mas também espaços de saúde tão exóticos como a Farmácia Islâmica de um Palácio na Síria, exposta no Museu da Farmácia do Porto. Ainda no período da Idade Média, damos a conhecer o módulo das Máscaras da Peste e a Luta Contra as Epidemias, onde, a par da atualidade, é feita uma perspetiva histórica sobre as grandes pandemias e as primeiras, as primeiras máscaras de proteção, a par da atual situação pandémica causada pelo novo coronavírus.
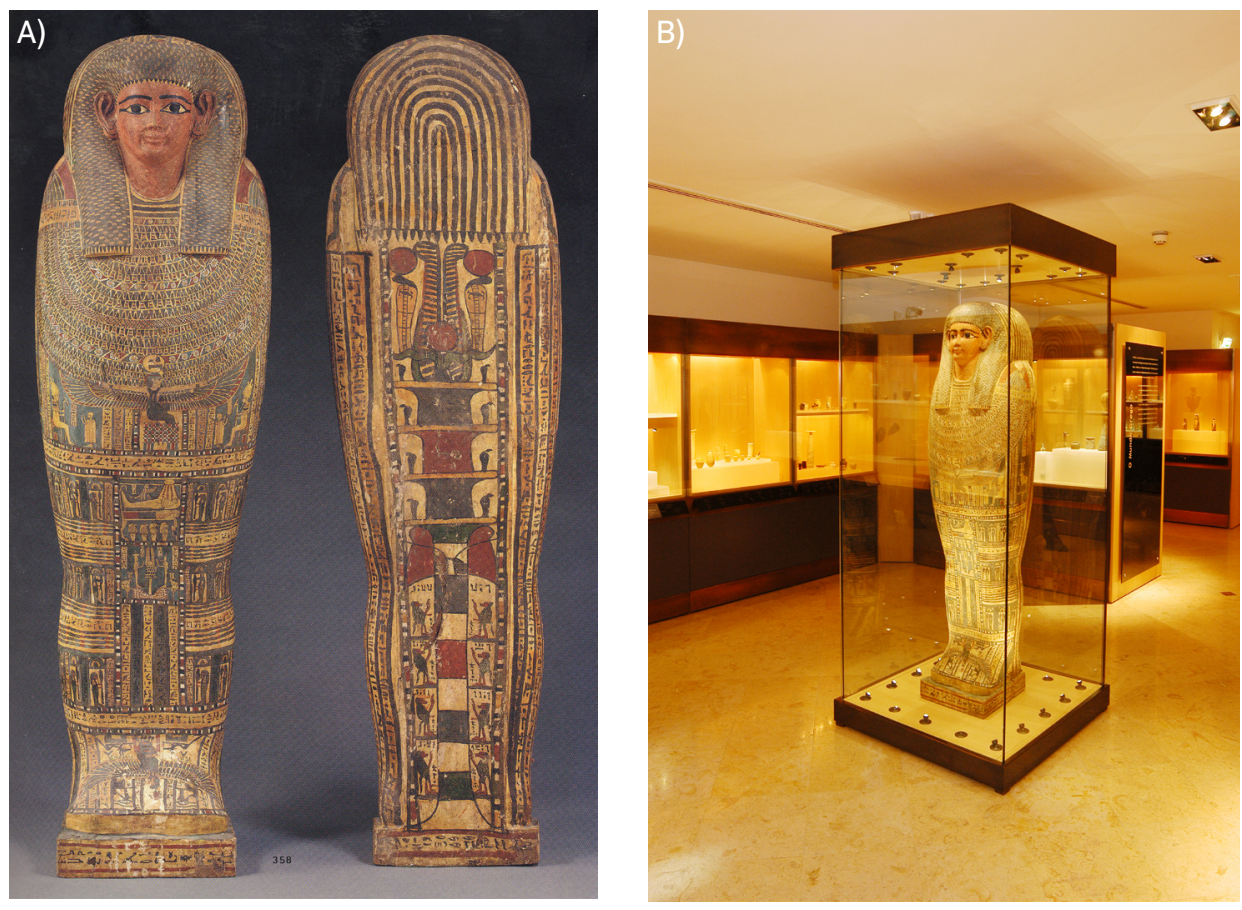

FIGURA 1. A) Sarcófago de Irtierut. B) Sarcófago em exposição.

Por forma a compreender não só como ultrapassar as doenças mais marcantes da história da saúde, mas também como a ciência se desenvolveu e abriu portas à modernidade, somos convidados a participar em grandes momentos de desenvolvimento cientifico, com o módulo 0 início da Revolução Cientifica, através das invenções de instrumentos que em muito impulsionaram o progresso cientifico, como os microscópios compostos de Edmund Culpeper, e a descoberta que o nosso corpo era químico. Sabendo que acontecimentos como a $1^{\mathfrak{a}}$ Guerra Mundial fazem também parte da história da humanidade, é para onde viajamos de seguida, acompanhados por Sir Alexander Fleming que, no núcleo A cultura de penicilina e a invenção dos antibióticos, nos apresenta a história da sua descoberta, que viria a mudar a luta contra as infeções.

Fazem ainda parte desta iniciativa, e por forma a evidenciar a globalidade dos temas saúde e farmácia, dois núcleos que evidenciam a multiculturalidade do acervo reunido. Desde 
a abordagem à "Medicina Tradicional Chinesa", onde encontramos uma das farmácias mais exóticas da coleção, a Farmácia Tai Neng Tong, até ao núcleo final: A Aventura do Homem. Neste último, somos desafiados a dar a volta ao mundo com diferentes aventureiros e exploradores, arriscando-nos desde os desertos e savanas africanas, até ao polo norte e polo sul, chegando até à Antártida, pela companhia de Roald Amundsen, que, assim como em todas as expedições representadas no Museu da Farmácia, se fez acompanhar por estojos e farmácia portáteis!

O Museu da Farmácia propõe assim, em 60 minutos, uma viagem por entre 5000 anos de história da saúde e da farmácia, passível de ser feita na segurança de cada casa ou escola, dando a oportunidade aos seus visitantes de conhecerem duas coleções, separadas por 300 quilómetros de distância, e que agora, foram reunidas para materializar uma única experiência interativa.

Poderá aceder a mais informações sobre estas visitas virtuais e aventurar-se nesta iniciativa em https://www.museudafarmacia.pt/museu.aspx?lang=pt\&id=1150. 